\title{
Vom globalen Bourgeois zum globalen Citoyen
}

$\mathbf{V B}$ verfassungsblog.de/vom-globalen-bourgeois-zum-globalen-citoyen/

Maximilian Steinbeis Fr 10 Mai 2013

Völkerrecht ist längst nicht mehr nur Völker-Recht. Nicht nur Staaten und Organisationen sind internationaler Rechte und Pflichten fähig, sondern auch Individuen. Ich als Einzelperson habe ein ganz individuelles Recht darauf, als Angeklagter in den USA konsularischen Schutz in Anspruch zu nehmen, als Investor in Bolivien nicht ohne Entschädigung enteignet zu werden, als Terrorfinanzierungsverdächtiger nicht ohne Begründung meine Konten eingefroren zu bekommen und als ziviles Opfer von Nato-Bombenangriffen unter Umständen auf Schadensersatz zu klagen. Das sind gar nicht unbedingt alles Menschenrechte, sondern eben einfach Rechte. Meine Rechte.

Anne Peters, die Basler Völkerrechtsprofessorin und frisch berufene Direktorin des Heidelberger Max-PlanckInstituts, ist derzeit Fellow am Wissenschaftskolleg und hat ein neues Buch zu dieser Thematik geschrieben, das demnächst erscheint. Ihre zentrale These hat sie am Montag im Wissenschaftskolleg zur Diskussion gestellt: Das primäre Völkerrechtssubjekt ist der individuelle Mensch. Er braucht keinen Staat, der als Treuhänder bzw. Vormund auf internationaler Ebene aufpasst, dass ihm nichts passiert. Das kann er selber.

Wie im nationalen Konstitutionalismus des 19. Jahrhunderts, so Peters, lässt sich der individuelle Mensch nicht mehr mit dem paternalistischen Versprechen des Staates abspeisen, unter seinem Schutz sein privates Hab und Gut mehren zu dürfen. Er ist nicht länger nur Objekt des internationalen Rechts, sondern sein Subjekt. Sein Menschenrecht auf Rechtspersönlichkeit ist nicht länger auf die nationale Ebene beschränkt, sondern erstreckt sich auch auf die internationale. Er hat teil an der Erzeugung des internationalen Rechts. Er ist kein globaler Bourgeois mehr - er ist globaler Citoyen!

Dass da der eine oder andere Völkerrechtler bzw. Politologe im Publikum energisch widersprach, überraschte niemanden. Zielt dieser Vorschlag eines internationalen subjektiven Rechts auf eine "umfassende Van-Gend-enLoosierung des Völkerrechts", auf eine Integrationsdynamik wie in der EU, nur im globalen Maßstab - mitsamt der dazugehörigen Ermächtigung der Justiz? Was wäre das anderes als ein "Misstrauensvotum gegenüber den politischen Instanzen"? Steckt hinter der Ausweitung subjektiver internationaler Rechte nicht der Versuch, sich politische Vorteile zu verschaffen, indem man etwas als Recht behauptet und somit dem politischen Streit zu entziehen versucht, was man politisch nicht durchgesetzt bekommt?

Es gehe ihr gar nicht darum, das Völkerrecht immer und überall individuell einklagbar zu machen, erwiderte Peters. Es gehe um die "konzeptionelle Basis", auf der erkennbar wird, welche internationalen Rechte und Pflichten Einzelne innehaben. Und was die Politik betrifft: "Alles Recht ist auch Politik." Recht werde durch Politik erzeugt, um dann der Politik Grenzen zu setzen. Dass durch Legalisierung politisch Umstrittenes unstreitig gestellt werde, sei zwar richtig. Aber das subjektive internationale Recht habe den Vorteil, dass wenigstens nicht mehr alles auf Basis der Menschenrechte abgehandelt werden müsse, also als noch höheres Recht, als "Superlegalisierung". Legalisierung sei immer noch besser als Superlegalisierung.

Dem Einwand, dieser Weg führe in den "Weltstaat", entkräftete Peters mit dem Hinweis darauf, dass eine solche subjektiv fundierte Völkerrechtsordnung natürlich nur dezentral und auf Basis kleinerer Durchsetzungseinheiten funktionieren könne.

Auch mit dem bürgerrechtlichen Optimismus, der in dem Begriff "Citoyen" mitschwingt, war nicht jeder einverstanden. Völkerrechtliche Verträge seien keineswegs immer Werkzeuge der Ermächtigung des Einzelnen, selbst wenn sie individuelle Rechte verleihen. Investitionsschutzabkommen beispielsweise - "wer ist das, der da klagt? Das globale Kapital! Das ist alles andere als der Citoyen." Womit Peters durchaus einverstanden war. Citoyen sei der Bürger, der an der Rechtserzeugung beteiligt ist. Der Investor, der ein Schiedsgericht anruft, wenn 
eine demokratisch legitimierte Regierung seine Businesspläne durchkreuzt, sei eben Bourgeois, kein Citoyen, zumal er nur Rechte hat, aber so gut wie keine Pflichten.

Manche wollten auch nicht ohne weiteres akzeptieren, dass der nationale Citoyen und der globale Citoyen immer an einem Strang ziehen. Ist nicht der Einzelne gerade auf den Staat angewiesen, um seiner Stimme auf internationaler Bühne überhaupt Gehör verschaffen zu können? Sie wolle die Staaten ja gar nicht zu Buhmännern machen, erwiderte Peters. "In Failed States geht es den Menschen am schlechtesten." Auch bleibe die Durchsetzung internationaler subjektiver Rechte immer noch in erster Linie eine Sache der Staaten. Trotzdem sei ein "gesundes Misstrauen" gegen die Staaten am Platze. Das Völkerrecht werde weiterhin in erster Linie durch Staaten durchgesetzt. Dennoch sei es nützlich, auch Rechte zu haben gegen Institutionen, die von Staaten eingesetzt wurden.

\section{LICENSED UNDER CC BY NC ND}

SUGGESTED CITATION Steinbeis, Maximilian: Vom globalen Bourgeois zum globalen Citoyen, VerfBlog, 2013/5/10, http://verfassungsblog.de/vom-globalen-bourgeois-zum-globalen-citoyen/. 